\title{
TREATMENT FOR RISING DAMP AND NATURAL HYDRODYNAMIC EQUILIBRIUM IN MASONRY WALLS
}

\author{
JOSE DOBÓN ${ }^{1 *}$ AND MIGUEL Á. SORIA ${ }^{2}$ \\ ${ }^{1}$ Civil Engineer \\ Kerakoll Ibérica S.A. \\ Carretera de l'Alcora, Km. 10,450, 12006 Castellón de la Plana, Spain \\ e-mail: jose.dobon@kerakoll.es \\ ${ }^{2}$ Building Engineer \\ Kerakoll Ibérica S.A. \\ Carretera de 1'Alcora, Km. 10,450, 12006 Castellón de la Plana, Spain \\ e-mail: miguel.soria@kerakoll.es
}

Keywords: Masonry, NHL mortar, Historic Heritage, Capillary Moisture, Damp Walls

\begin{abstract}
The water absorption, in the Historic Heritage Restoration, through porous materials of the different constructive elements, is certainly one of the factors that constitute the basis for most pathologies and degenerative phenomena on plastering and masonry walls. Particularly, the most critical humidity comes from the soil, because it contains salts (chlorides, sulphates, nitrates). Those salts impregnate the masonry and unleash humidity rises up to several meters. Humidity varies the physical and chemical behaviour of the wall, increasing the thermic conductivity and limiting the isolation power. In addition, due to surface crystallization of the salts, early disintegration of the building materials and rapid destruction of the wall are generated. A wall saturated with water diminishes its isolation power and favours the formation of mould and bacteria, worsening the healthiness of the environments and the well-being of the people who habit them. In nature, a natural hydrodynamic balance is established between the water absorbed by building materials through capillarity and osmosis, and the water transferred to the atmosphere through evaporation. The constant components within this equilibrium are the absorption of water through capillarity and osmosis of the building materials, and the chemical nature of the aqueous solution absorbed. The variable components are the temperature and relative humidity of the atmosphere. The evaporation surface, composed by masonry mortar, plastering, scraping and painting are the constructive elements on which we might make an intervention. The traditional constructive systems, exclusively based on using natural lime for the manufacture of masonry mortars and rendering, and on using lime paste for coatings and paints, used to create the natural effects of the breathable hydrodynamic balance of the masonry. The challenge is to reproduce today, on site, a range of natural lime products in order to carry out interventions completely comparable to the original construction techniques. The range of naturals products, ensures a natural balance between rising damp and surface humidity evacuation, exploits the natural qualities of microporosity and hygroscopicity of the NHL, and natural pozzolan. The lack of reaction with the salts ensures chemical stability of the rendering and the duration of the entire dehumidifying system. The aim of the paper is to present real cases.
\end{abstract}




\section{INTRODUCTION}

Walls are all potentially absorbent and suffer from contact with water. In particular the most critical form of humidity is that deriving from the ground, as it is loaded with salts (chlorides, sulphates and nitrates) that impregnate the wall and trigger capillary moisture rising that can reach heights of several meters.

Damp changes the physical and chemical behaviour of the wall, increasing thermal conductivity and restricting the insulating capacity. Furthermore, due to the surface crystallisation of the salts, it causes early crumbling of the construction materials and rapid destruction of the wall. A wall that is saturated with water has a lower insulating power and encourages the formation of moulds and bacteria, worsening the health of rooms and the wellbeing of those living in them.

\section{DEHUMIIIFICATION HISTORY}

Historically, different systems have been used trying to solve the moisture rising on walls. Leaving aside the well-known "trasdosado" system due to its proven inefficiency, below we chronologically list the different systems employed for dehumidify walls.

\subsection{Moisture control with waterproofing (50's)}

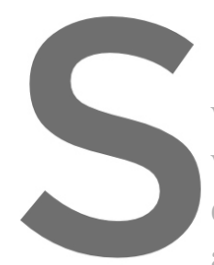

The first attempts waterproofing the surfe waterproofing agents us even the lining of the wall and saline wall.
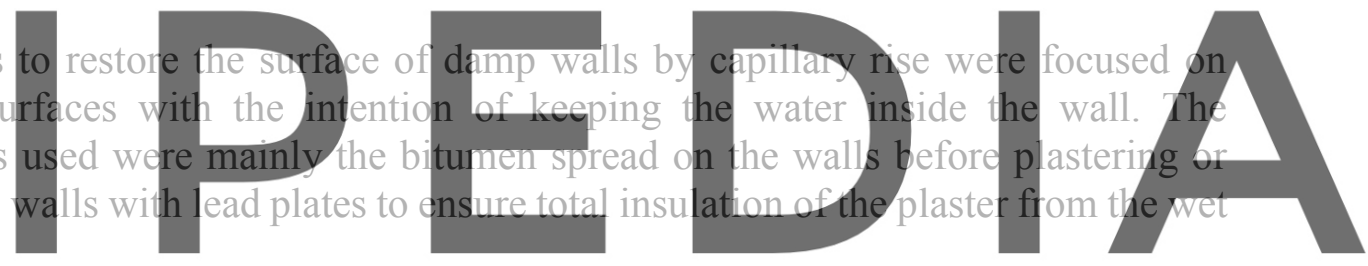

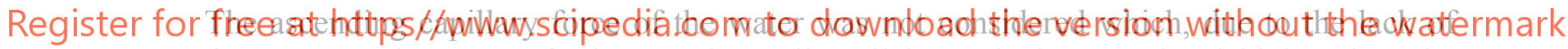
surface evaporation, went further up the wall until it reached a new level higher than the previous one.

\subsection{Mechanical cutting and aerator siphons (60's)}

These systems, which seek to prevent moisture to climb the wall upwards, fail to desalinate the wall and therefore leaves it highly hygroscopic, so it does not solve one of the factors that causes mortars degradation.

\subsection{Chemical cutting systems (70's)}

This system consists of injecting resins into the base of the wall that waterproofs it. As before, this system fails to solve the crystallization of salts on the wall surface and causes the surface degradation of the building elements (renders, mortars, plasters, stons, bricks)

These systems are the precursors of sacrifice mortars 


\subsection{Macroporous mortars for cortical dehumidification (80's)}

A first attempt to dehumidify through the use of semi-breathable aerated cement mortars involved waterproofing the surface of damp walls with the application of osmotic base mortar to reduce (at least "50\%") the contribution of humidity and salts. The operation of aerated cement mortars was based on foaming additives which, during the mixing phase, generated macroporosity intended for the crystallization of the salts inside the mortar.

The limited durability of the system depended on the clogging speed of the macropore capacity which saturated allowing the reappearance of salts and moisture on the surface. This is why they were called sacrifice mortars.

\subsection{WTA dehumidifying systems (1985)}

The technical requirements for cortical restoration mortars are established for the first time. It includes both lime mortars and cement mortars.

\subsection{CE mark (2000)}

European standard EN 998-1, Specification for mortar for masonry - Part 1: Rendering and plastering mortar. The Type $\mathrm{R}$ are the Renovation mortars (the cortical restoration mortars).

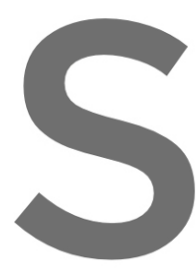

This standard establishes strength, adhesion and fracture capillary water absorption, vat reactions to fire.

2.7 Natural microporous mortars for cortical dehumidification (2005)
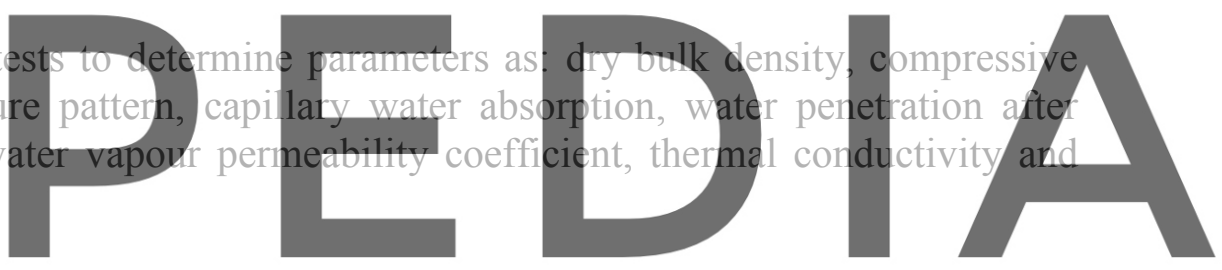

Register for free at https//www.scipedia.com to download the version without the watermark

In 2005, thanks to the contribution of Kerakoll in research on natural limes and pozzolans, a new naturally breathable, salt-resistant mortar was found which complies with the requirements of the WTA and the EN 998-1 Type R, Biocalce Zoccolatura.

\subsection{Biocalce MuroSeco: The first mortar that dries the wall in depth by dehydration (2016)}

This special mortar for dehumidification guarantees a natural balance between moisture rising and surface dispersal of the humidity, taking advantage of the natural micro-porosity and hygroscopic qualities of pure NHL lime and natural pozzolan.

The fact that it does not react with the salts ensures that the render is chemically stable and makes the entire dehumidifying system more long-lasting.

The birth of the first natural lime and puzzolan mortar/render for long-term cortical dehumidification. 


\section{BIOCALCE MUROSECO FEATURES}

\subsection{The pure natural hydraulic lime that breathes}

Nature has taught us the secret of how to make walls breathable. This line of natural mortars are a simple, natural materials whose porosity, breathability and hygroscopic qualities allows a continuous interchange of air and vapour within the wall, keeping the house healthy and in perfect equilibrium.

The quality of the natural hydraulic lime NHL 3.5 and selection of the natural elements gives this mortars greater natural porosity, compared with cement based plasters and renders, acting as a true "hygrometric lung" on the wall and providing a perfect balance between strength and elasticity, making this line of natural products perfectly compatible with even deteriorated walls and increasing indoor liveability

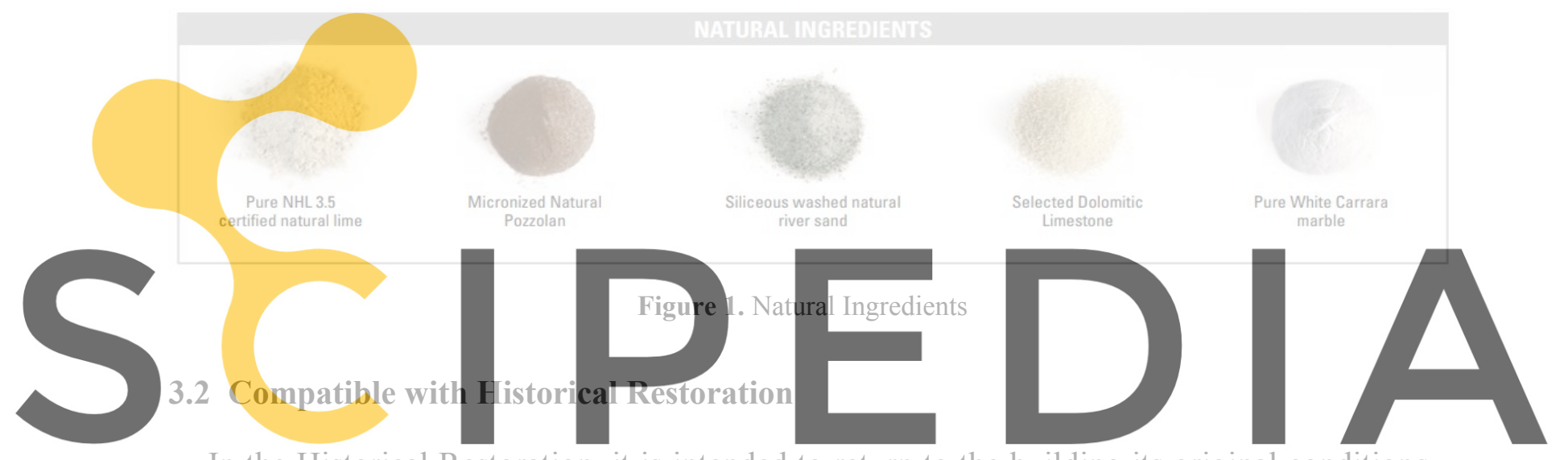

In the Historical Restoration, it is intended to return to the building its original conditions,

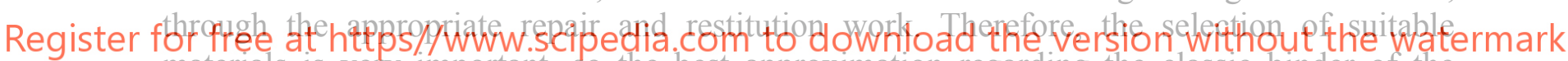
materials is very important, so the best approximation regarding the classic binder of the original mortars is natural lime.

Natural lime mortars are easily reversible materials. It will be necessary to take into account when restoring, that this will not be the last, but that in the future there will be maintenance and other interventions in the same heritage.

This naturals mortars is indicated for the Restoration of Historical Heritage since:

1. Respect tradition, ensuring complete affinity with the materials and construction techniques of historical heritage.

2. Its high porosity, low capillary absorption and high breathability make it ideal for the rehabilitation of historic buildings, even in the presence of moisture.

3. It is resistant to salts, thanks to the lime and pozzolan that make the NHL mortar insensitive to the attack of disintegrating salts.

4. Recreate the original colors. Lime colors and natural earth and oxides return to the original tones of the old colors guaranteeing an optimal and complete conservative restoration. 


\subsection{The secret of its active pore}

The size of the ACTIVE MICROPORES in the special dehumidication mortar guarantee high levels of breathability and very low capillary absorption. The small diameter of the capillary channels blocks the passage of water, which does not get into the render, while it allows free passage of the vapour molecules.

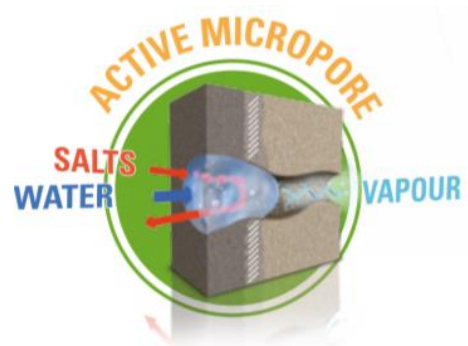

Figure 2. Avtive Micropore

\subsection{The natural lime-pozzolan that is insensitive to sulphate attack}

Kerakoll's research technicians have managed to identify a natural pozzolan that, thanks to its origin and grain size, makes the natural hydraulic lime nhl 3.5 insensitive to sulphate attack.

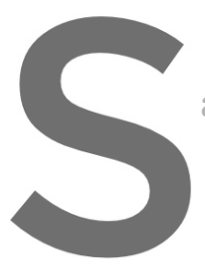

The chemical resistance of

an analysis method kno

5. The method involves preparing test sanip dried and then g
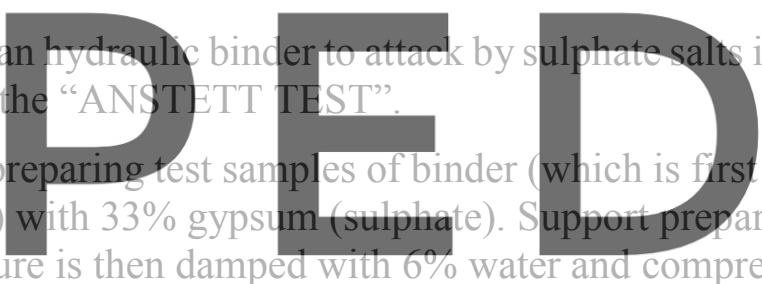

6. The new powder mixture is then dampedi mould to form a cylindrical pellet of standard dimensions ( $\varnothing 80 \mathrm{~mm})$

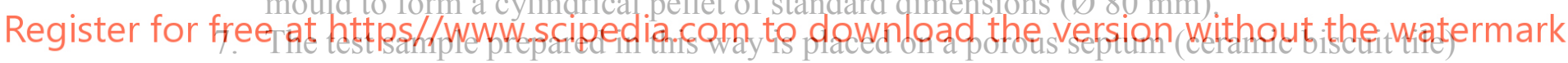

in permanent contact with water.

8. The reaction to sulphates is checked by measuring the diameter of the pellet at reguiar intervals using a precision gauge $( \pm 0.01 \mathrm{~mm})$.

The measurement express the percentage increase in diameter from the start of the test.

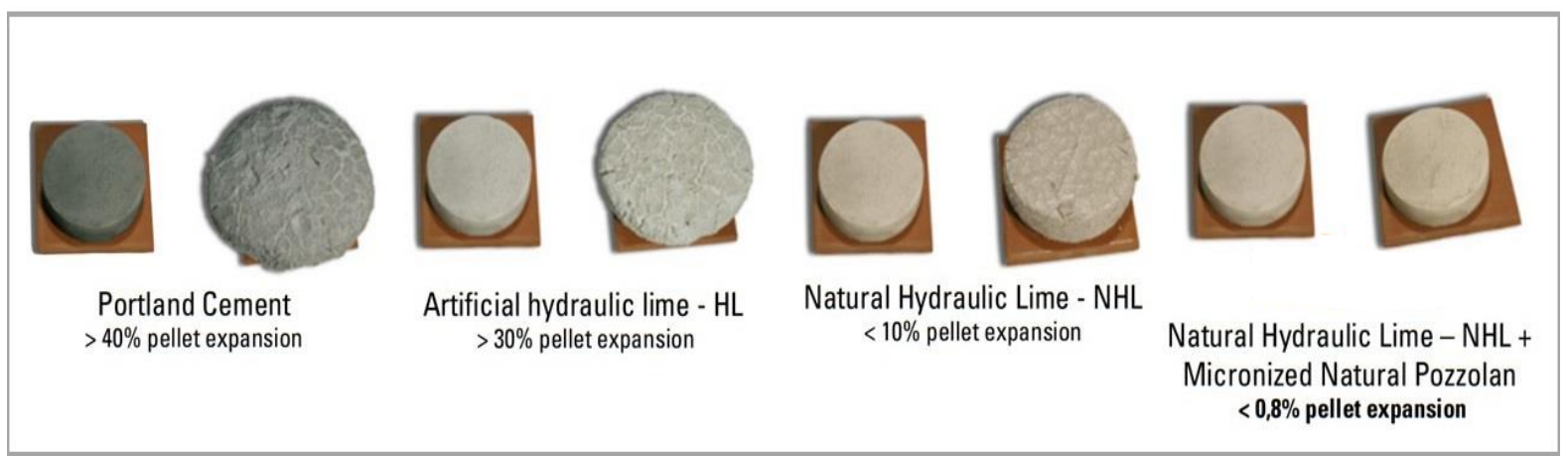

Figure 3. Anstett Sample 


\section{STUDY CASES}

The following study cases represent some examples of works carried out with the micropore dehumidifying system in 2004 and 2013. Two case studies are shown: one of them is a dehumidification of the barrel vaults of the "Fuerte Victoria Grande" in Mellila (Spain), and the other is a dehumidification of the "Limonaia" building of the Boboli Garden in the Pitti Palace of Florence (Italy).

\subsection{Barrel vaults - Fuerte Victoria Grande - Melilla}

The Fort Victoria the Great (Military Engineer Juan Martín Zermeño, 1735-1736) and his defensive perimeter is part of the system of the Fourth Precinct Fortified Melilla. It all starts with the intention of rescuing the soul buried under the old prison's debris in the eighteenth century Fortification, incorporating traces that allow us to know part of the life of the building over the time. We develop a historical collage flavoured with the beautiful ruins found in the present archeological finds and hue of contemporaneity that contextualizes the intervention of rehabilitation.

The intervention with this dehumidifying system is concentrated in the barrel vaults that form the galleries of the fort. These vaults are mixed with masonry base and brick arch, and there was moisture, both rising and roof water filtration. After waterproofing the roof, the strength of the support was ovaluated and the suitability of the dehumidifying $\mathbf{s}$ ystem was
confirmed.
After applying the pure NHL lime and pozzolan dehumidifying mortars a lime-based ronder
compatible with the system, was applied. As a decorative and projective layer, it was painted
with breathable paint based on pure silicate according to Din 18363 that gtrarantees the continuity of dehumidification.

Register for free at https//www.scipedia.com to download the version without the watermark
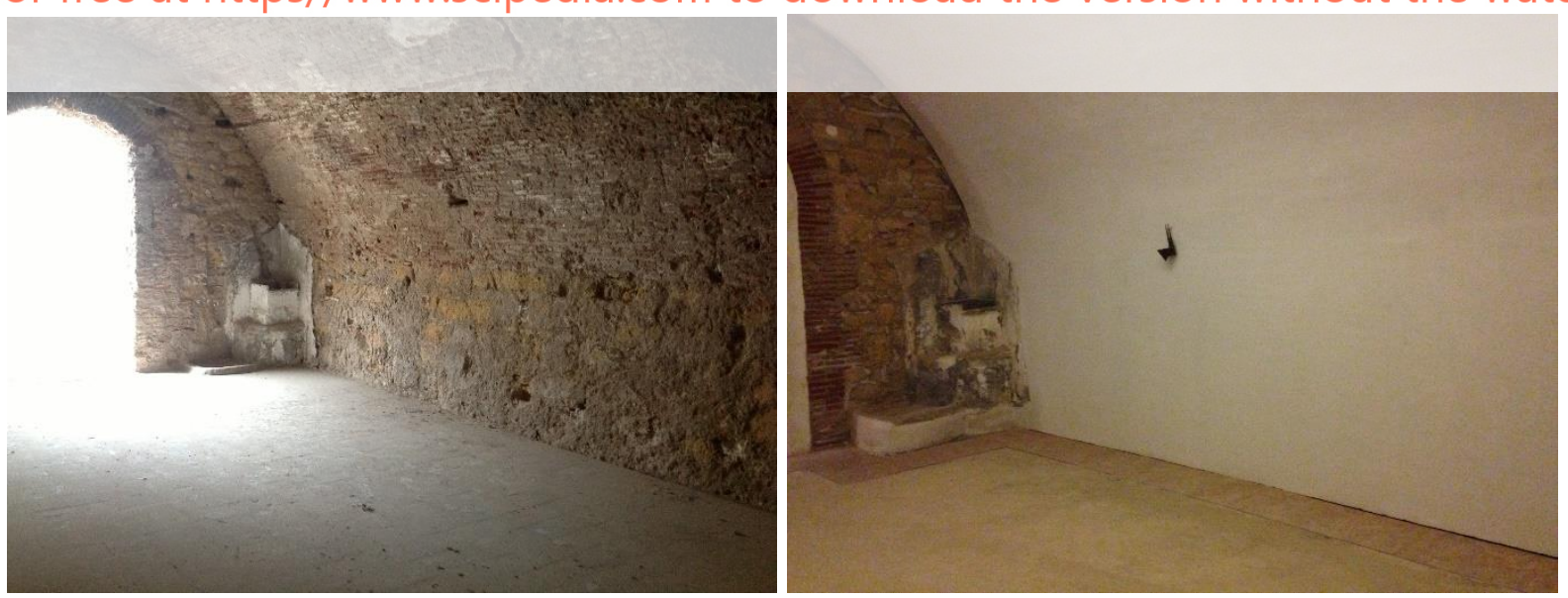

Figure 4. Previous and current status of one of the vaults 


\subsection{Masonry wall - "Limonaia" of the Boboli Garden - Florence}

Built between 1777 and 1778 to a design by Zanobi del Rosso, the 'Limonaia' is the Boboli Gardens most characteristic building, which has come to us almost intact, thanks to the continuity of use that has been made. The building, in fact, is still used as a shelter of citrus collections (about five hundred pots), highly appreciated by the Medici, both for the therapeutic and aromatic qualities of the fruit, and for its beauty and singularity. The facade, one of the few examples of rococo taste present in Florence, still preserves original mortars and fixtures.

The restoration of the 'Limonaia' involved the roof, the interior and the main facade of the building and the elevations of the side rooms. Particular attention was paid to the restoration of the main front mortars on which two surveys were carried out with stratigraphic tests in 1997 and 2002, which made it possible to draw up a careful mapping of the degradation and led to the choice of an accurate methodology intervention for mortars and paints, conducted in the same way that guides the restoration of the wall paintings. The philosophy of the intervention was to consolidate and preserve all that was possible to save of the original mortar, avoiding indiscriminate removal and subsequent remaking with new mortars.

It is for this reason that the project was chosen by the European Heritage Laboratory as an example of methodological reference for any safeguard and conservation intervention of plaster of historical value that still exists.
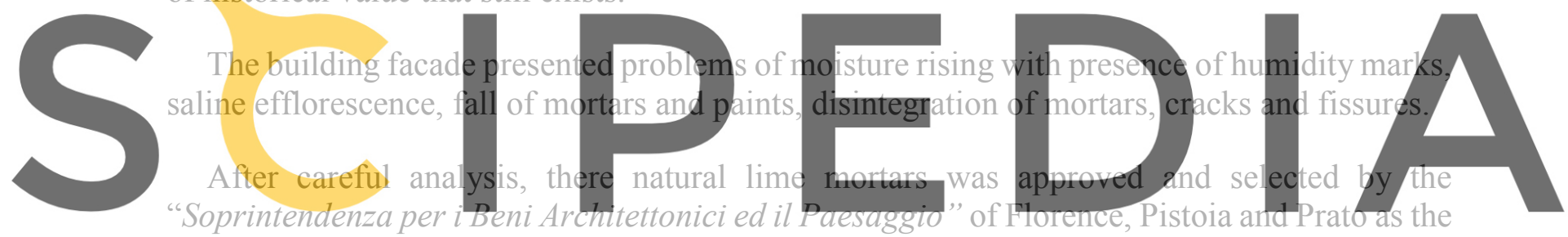
most appropriate solution to guarantee the recovery and conservation of the 'Limonaia' of the

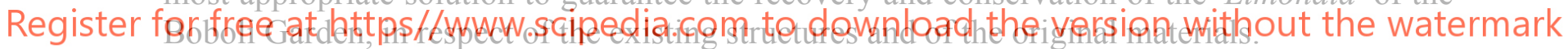

This natural line of products, based on pure natural lime NHL 3.5, has been proposed as a suitable solution for the conservative restoration of the mortars of historical and monumental buildings, thanks above all to its characteristics of porosity, breathability and hygroscopy that allow a continuous exchange of air and steam inside the masonry.
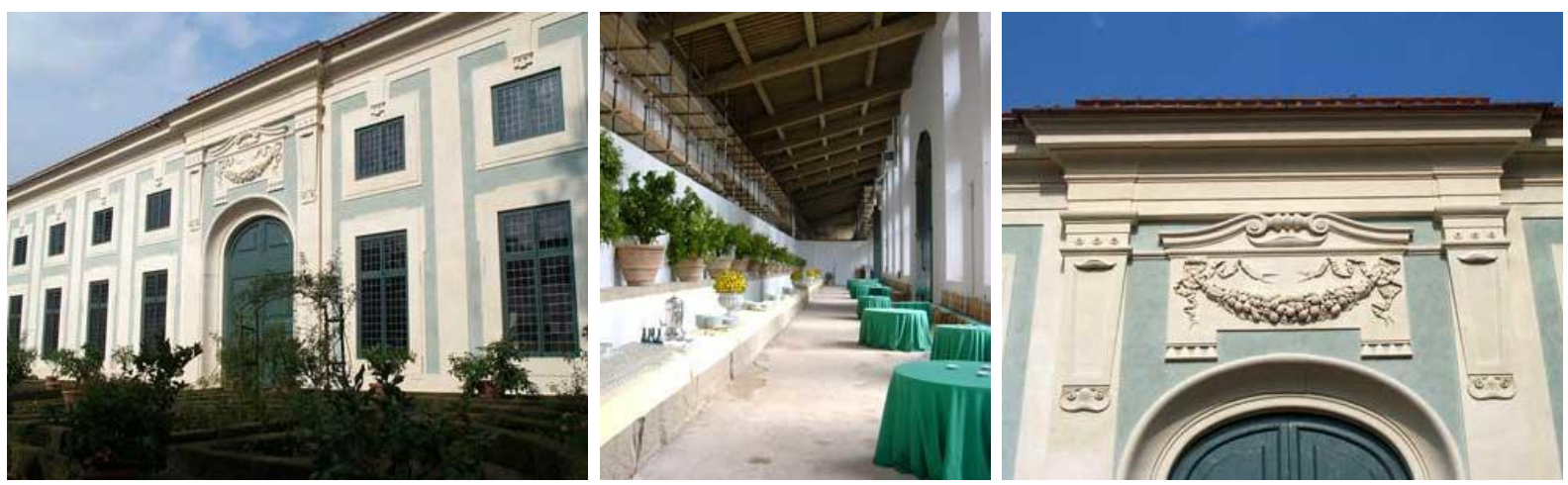

Figure 5. Limonaia post-restauration 2004 


\section{CONCLUSIONS}

Since the 80 's, sacrifice mortars have been used as the best solution available to try to reduce the effects of moisture rising. Many times these mortars have been cement based which have produced irreparable damage to the historical heritage. The use of sacrifice mortars of pure natural lime NHL compatible with historic buildings, thanks to its behavior more similar to the original materials, often managed to delay the appearance of the moisture rising without damaging the heritage but requiring periodic maintenance of the mortars. Only the combination of natural pure lime NHL wisely dosed with natural pozzolan and selected aggregates achieve a highly breathable mortar with a micro-pore configuration that prevents the mechanical attack of salts. On the other hand, this combination of elements is what also makes the mortar resistant to the chemical attack of the salts, thus solving the moisture rising problem in a lasting way without the need to carry out constant maintenance tasks and which, with the over the years, dry the wall affected by moisture rising.

The studies and the different applications carried out with this micropore dehumidifying mortars, have shown, after years of correct behavior in real cases, that this dehumidification system is the most appropriate, not only to solve the problem of moisture rising, but also the more compatible in historic buildings, thanks to its mechanical and performance characteristics very similar to that of the original materials.

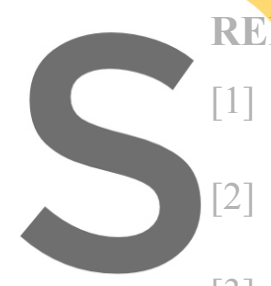

REFERENCES
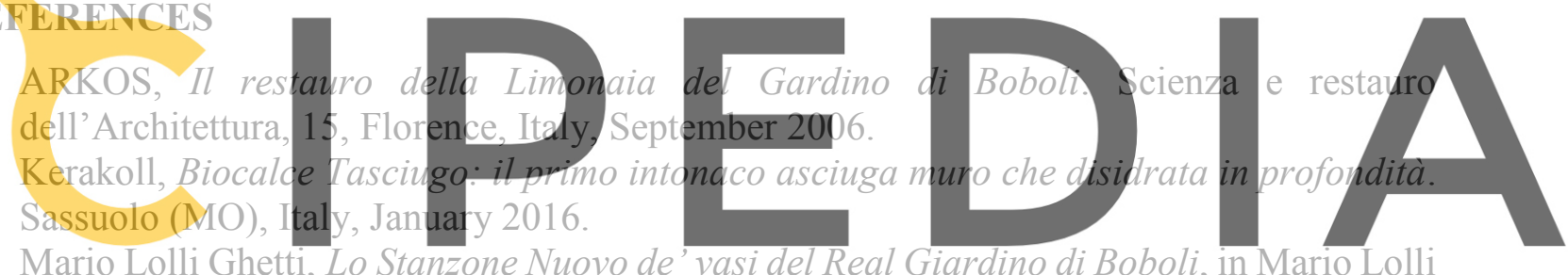

Mario Lolli Ghetti, Lo Stanzone Nuovo de vasi del Real Giardino di Boboli, in Mario Loll Register for free at Gttps fwwww.Scipedia.com to download the version without the watermark

[4] Loris Stefanini, La 'fabbrica' della Limonaia tra Sette e Ottocento, in Paola Grifoni (edited by), La Limonaia del Giardino di Boboli. Storia e restauro, Livorno, Sillabe, 2005, pp. 33 35, with previous bibliography.

[5] World Monuments Fund, Limonaia at Boboli Gardens and Garden of Villa Medici At Castello. New York, EU. Recovered from http://www.wmf.org

[6] Loris Stefanini, Modifiche e trasformazioni tra Otto e Novecento, in Paola Grifoni (edited by), La Limonaia del Giardino di Boboli. Storia e restauro, Livorno, Sillabe, 2005, pp. 3637, with previous bibliography.

[7] Loris Stefanini, L'intervento di restauro, in Paola Grifoni (a cura di), La Limonaia del Giardino di Boboli. Storia e restauro, Livorno, Sillabe, 2005, pp. 62-73, with previous bibliography.

[8] José Antonio Fernandez Fernandez, Rehabilitaton Works on the 4th fortification in Melilla: "Victoria Grande fortress" and "Covered Path", Akros: Revista de Patrimonio, Spain, ISSN 1579-0959, No. 14, 2015, págs. 55-62 